\title{
ResearchOnline@JCU
}

This is the Accepted Version of a paper published in the journal: The Journal of Educational Policy

Salter, Peta (2014) Knowing Asia: creative policy translation in an Australian school setting. Journal of Education Policy, 29 (2). pp. 145-164.

http://dx.doi.org/10.1080/02680939.2013.794303 


\section{Knowing Asia: creative policy translation in an Australian school setting}

Policy implementation at school level is often recognised as transformative

enactment. Positioning school leaders as gatekeepers in this enactment is limiting. This study of one Australian school explores the complex contextualised agency of school leaders showing that their role, far more than gatekeeping, can be enabling and transformative. Identifying the agency of school leaders in enacting policy imperatives to 'know Asia' creates space to imagine localised narrative possibilities that negotiate and potentially challenge policy agendas. Accounts of policy work by school leaders are heteroglossic and densely intertextual in their mobilisation and collocation of discourses. A metaphor of a frog in a well is taken up to translate policy in locally specific ways that make it much more than a template of externally devised policy. Deep contextual knowledge empowers school leaders to imagine policy in innovative ways; however it is paired with a cautionary note on risks inherent to shaping policy for 'like-minded' futures.

Keywords: policy enactment, agency, Australia-Asia, heteroglossia

\section{Introduction}

In Australia, significant focus on Australia-Asia relations manifests in a combination of national policy moves that call for Australia to 'know Asia'. Firstly, the White Paper Australia in the Asian century offers a distinct imagining of Australia's future engagement with Asia. Commissioned "to consider the likely economic and strategic changes in the region and what more can be done to position Australia for the Asian Century” (Australian Government 2012) it describes its purpose as a "national blueprint for a time of national change” (Henry 2012, p. 3) and "roadmap for the whole of Australia” (Commonwealth of Australia 2012, p. 1). It is a future-orientated policy that cites a critical need for “'knowledge, skills and mindset[s]' for successful engagement in Asia (Asialink 2012)” (Commonwealth of Australia 2012, p. 180). Secondly, the emerging National Curriculum includes the cross- 
curricular priority 'Asia and Australia's engagement with Asia', which requires that "students learn about and recognise the diversity within and between the countries of the Asia region” (ACARA). School leaders are considered crucial catalysts (AEF 2006b; 2008; 2012a; b; c; McRae 2001; Owen et al. 2006) for realising these policy imperatives in schools and ensuring future generations 'know Asia'.

The ability of school leaders to frame these policies as meaningful and purposeful change for the school itself is paramount. Contextual factors intimately shape this policy enactment, despite neglect of correlating constraints and enablers noted in much central policy making (Ball 2011, p. 585). These factors are heteroglot, dialoguing with each other in a variety of ways in "complicated, nuanced, interdisciplinary conversations about school knowledge, self and society” (Ylimaki 2012, p. 308). Positioning leaders as Ball (1993) does as 'gatekeepers' in this process might be limiting, if it is taken as a need to guard the school against intrusion from external forces. It illuminates mechanistic, rather than imaginative work many leaders do to interpret and translate policy in highly creative, sophisticated and contextualised ways (Braun et al. 2010, p. 549).

An Asian proverb that a frog living in a well can see only a small circle of sky is used as a metaphor for translation work in this study. School leaders use the proverb to rationalise 'knowing Asia' as a way of challenging the narrow mindedness of small-place perspective, transforming policy discourse to create a new conclusion for the proverb - that 'knowing Asia’ can broaden perspectives and help frogs escape the well. This narrative is heteroglossic, mobilising multiple intertextual motifs that draw from policy and various 
discursive frameworks. It re-orientates the policy imaginary and demonstrates leaders’ agency to negotiate policy as text.

Economic and human capital knowledge, inferred from neoliberal economic thinking (Rizvi and Lingard 2010), pervade the perceived need to 'know Asia' . This thinking is characterised by a tendency to take an instrumental approach to 'knowledge' in policy. The 'knowledge economy', positioned as an extension of a neoliberal paradigm of globalisation that views education in strictly functionalist terms, can be contrasted with a broader notion of the 'knowledge society' that encompasses education for social inclusion and informed citizenship (Peters 2001, p. 13). Many traditionally western educational contexts that have realised that an education-based strategy may be essential to economic engagement with Asia (Pang 2005) operate within this tension. Asia programs demonstrate the rising prominence and importance given to 'knowing Asia' and take various forms of cultural and/or language studies, embedded or positioned discretely within curriculum. In Australia, 'knowing Asia' is commonly referred to as 'Asia literacy'; “knowledge, skills and understandings of the histories, geographies, arts, cultures and languages of the diverse Asian region” (AEF 2012d, p. i) ${ }^{1}$. Asia literacy is underpinned by an economic rationale to develop an Australian "export culture which is “Asia-literate’”(Rudd 1994, p. 2), aiming to produce an Asia-literate generation to boost Australia’s international and regional economic performance (Henderson 2003). While undoubtedly part of a larger response to global economic shifts, this rationale has been challenged as a " neo-colonial project which aspires to understand the object of Australia’s economic desires” (Singh 1995, p. 9). Overall, it positions education as both essential to, and destructive of Australia's economic interests (Singh 1995), invoking Asia literacy as a necessary solution for a prosperous future (Salter 2013). 
Initially, take-up of Asia literacy was at the discretion of individual schools. The Asia Education Foundation (AEF) sought to promote this take-up through position statements deployed as extensions of government policy and reports (AEF 1995, pp. 2-3). Constitutive competitive and economic discourses in curriculum policy documents such as the National Statement for Engaging Young Australians with Asia in Australian Schools (AEF 2006b) and National Statement on Asia Literacy in Australian Schools (AEF 2011) potentially limit enactment of Asia literacy. These discourses align with purposes of social mobility, potentially constraining schools to focus only on those Asian countries that are prominent in trade relations, such as India or China. In this vein, the White Paper Australia in the Asian Century prioritises "the current and likely future course of economic, political and strategic change ... encompassing China, India, the key ASEAN countries as well as Japan and the Republic of Korea” (Australian Government 2011). In contrast, discourses of harmonious, intellectual and cultural engagement with Asia are present and resonate in rhetoric of umbrella policy documents, such as the national statement on education the Melbourne Declaration of Educational Goals for Young Australians, reorienting education for public purposes (Cranston et al. 2010). This slippage creates both opportunity and confusion for school leaders, opening spaces for multiple responses to policy across different school contexts.

The primary focus of this article is the overarching vision and metaphor that embodies policy take-up and acts as a catalyst for curriculum reform, rather than the detailed particularities of curriculum enactment. It contributes to a critically informed "toolbox of diverse concepts and theories” (Ball 1993, p. 10) for education policy analysis, focusing on the context(s) of practice of the policy cycle (Ball 1994a), particularly policy to context (Ball 1993). Analysis draws on a Foucaldian notion of discourse as socially produced forms of 'knowledge' that are 
commonly accepted as 'truths' (Bacchi 2009) and in some way constitutive, rather than reflective of the world. Though these 'truths' challenge the agency of those engaged with discourses to speak outside the positions and terms of reference discourses construct (Bacchi 2009; Ball 1993), they contain tensions which enable disruption and manipulation. This article takes up Grimaldi’s (2012, p. 1) call “to analyse how people can make a difference exerting their agentic powers” in discursive articulation; however, it diverges in its empirical "take up [of] the challenge...to relate together analytically the ad hocery of the macro with the ad hocery of the micro” (Ball 1993, p. 10). Situated within an understanding of globalisation, the exploration of heteroglossic discourses at the moment of policy to context (Ball 1993) makes visible the complex creativity of policy translation as it is enacted to know Asia. First, the article summarises conceptualisations of the role of school leaders as gatekeepers/visionaries in policy trajectories. Second, the paper establishes the conceptual framework and method of the study. Next, the frog metaphor is investigated using a derivative of Bakhtin's concept of heteroglossia to explore how school leaders translate policy in localised context. This exploration identifies discursive threads in the institutional narrative that intersect and re-imagine the metaphor through a narrow/broad binary. Finally, the paper discusses implications of this translation and agency of leaders to shape policy articulation.

\section{Policy trajectories}

This article is situated in a wider framework of policy trajectories. Policy trajectory studies serve to highlight the complexity of relating analytically the macro with the micro as in some ways separate, but inherently interconnected, contexts (Ball 1993; Gale 1999). Original conceptualisations of policy trajectory define three contexts of policy-making; "the context of 
influence, the context of policy text production and the context(s) of practice” (Bowe, Ball with Gold cited in Ball 1994a, p. 26). Each context is embedded in and requires an understanding of the others, exploring the policy cycle as "a heuristic and tentative exploration of the social phenomenon - policy- as something we confront, inhabit and respond to” (Ball 1994b, p. 108), to investigate both enacted and espoused policy.

A fundamental conjecture of policy trajectory is that policy making processes continue beyond completion of a physical policy text. Key to this is a recognition that policy texts are "not necessarily clear or closed or complete” (Ball 1993, p. 11), allowing meaning to shift and change in different contexts. This also raises the notion of policy as text and discourse. Attending to policy as discourse genealogy and how problems are represented opens space for investigation of the representational history of policy as text both at the macro and micro level. However, just as policy that arrives at the school has a representational history, the school institution itself does not exist in a vacuum and localised contextual factors act in significant ways to affect, inflect and deflect policy (Ball 1993, pp. 11-12). This highlights a dynamic relationship between constraint and agency for actors of and within policy. Differentiation between conceptualisations of policy as text and policy as discourse (Ball 1993) creates an untenable separation of approaches that more clearly operate in complementary and simultaneous ways (Bacchi 1999; 2009; Miriam Henry 1993; Nudzor 2009). Rather than position the two as discrete approaches, awareness of both as analytical tools greatly enriches analysis of the complexity of policy enactment. This enables a constructive questioning of policy (Bacchi 2009), allowing “more time theorising the 'space for challenge’” (Bacchi 2000, p. 55). 
School leaders engage with constructive questioning of policy at the school site. Relied upon to relate policy to context, they can be positioned as gatekeepers (Ball 1993). The notion of gatekeepers however is not always accurate. In many ways, it is an inadequate and restrictive term. While policies, as "textual interventions into practice” (Ball 1993, p. 12) constrain leaders in some ways with particular problems posed, they do not necessarily delimit space for action in localised responses, making it unnecessary in many cases to default to 'guarding against' external policy. It is often the role of school principals or curriculum leaders to take the first steps to enacting policy. These key mediators of policy serve to introduce the local particularities of policy enactment, often through the construction of narratives that rationalise school change. Commonly conceptualised as narrative of the future, it is one "that is better in some important ways than what now exists" (Bennis cited in Ylimaki 2006) and is closely intertwined with leaders' aspirations for the school (Leithwood et al. 2008). The notion of leader as visionary intersects with Ball, Maguire, Braun and Hoskins’ (2011) findings. They found that principals and senior leadership teams take up positions as 'narrators', who interpret, select and enforce meanings of policies. Key to this role is the articulation of an "“improvement plot' of some kind” that serves to "join up disparate policies into an institutional narrative”(Ball et al. 2011, p. 626). In some cases this is achieved through a “"principle of integration', which coheres policy and the school itself” (Ball et al. 2011, p. 627). The integration and fusion of seemingly disparate policies involves “creative social action not robotic activity” (Ball 1993, p. 12). Leaders’ work is imaginative; proactive in appropriating policy, rather than repudiating it in attempts to guard the school from apparently unrelated policy. This transformation work requires that school leaders be active agents in “changing the landscape”(Newman 2005, p. 724) at the localised context of the school and more broadly within state and federal contexts of educational reform. Newman (2005) suggests that this agency can be exercised through managerial 
assertiveness: drawing on policy discourses to drive through change that might otherwise be blocked; repackaging policy to meet local agendas; and privileging social agendas to re-work responses to meet social problems. This process of discursive articulation positions school leaders as "policy makers or potential makers of policy, and not just the passive receptacles of policy”(Ozga 2000, p. 7).

School leaders are constituted as key agents within the Australian programme of reform to ‘know Asia’. Leadership and advocacy within school administration is noted as a key priority for engaging schools with Asia literacy (AEF 2006b; McRae 2001). As formal school leader, the principal holds unique responsibility for policy decisions made at the school level and is positioned as the main source of leadership in schools and greatest influence in all schools (Day et al. 2010; Glen 2009; Leithwood et al. 2008). This is reflected in the Leading 21st Century Schools: Engage with Asia (L21CS) program that identifies principals as key leaders and 'targets' for facilitating the implementation of Asia literacy, signalling an anticipated transformational capacity of school leaders to "change the landscape” of the micro-politics (Newman 2005, p. 724) of 'knowing Asia'. The decision to target principals within school leadership teams was based on findings of The Future of Studies of Asia and Australia in Australian Schools: An Evaluative Investigation (Owen et al. 2006), which identified the need to persuade principals for school change with a clear rationale or justification for including studies of Asia and Australia in the curriculum. The Australian Government Department of Education, Employment and Workplace Relations (DEEWR) funded an A $\$ 1.5$ million three year project "to build a national cohort of Principal 'champions' to increase the uptake of the National Statement for Engaging Young Australians with Asia in Australia Schools” (AEF 2008, p. 1). The National Statement, endorsed by the Ministerial Council on Education Employment, Training and Youth Affairs 
(MCEETYA) in 2005, identifies “active support and involvement of school leadership” (AEF 2006a, p. 13) as the first indicator of significant progress in establishing a central focus on Asia literacy. Recent AEF releases ( 2012a; b; 2012c) reaffirm this indicator. Furthermore, mandating Asia literacy in the National Curriculum has dramatically increased the imperative for the L21CS program to engage principals in developing clear articulations of Asia literacy.

\section{Conceptual framework and method}

This study explores how Asia literacy is represented by leaders, particularly how espoused policy is translated at the school site. As a case study results are not generalizable; however, the intent of the trajectory project is to explore not "explain” (Ball 1994a, p. 108) policy to highlight the richness of policy analysis that takes localised enactment as fundamental to policy understandings. Therefore, selection of the case study site was purposive to ensure a school actively involved in the take-up of Asia literacy.

Ibis State High School (pseudonym) (Years 8-12) is one of the larger government secondary schools in Queensland, Australia. Situated in a regional city (Birdtown), the school positions itself as a leader in multiple curriculum areas and has a strong internationalisation agenda which includes affiliation with international bodies. The student profile is varied. Distinctive features include students from low socio-economic status (SES) and an enrolment of Aboriginal and Torres Strait Islander students which sits significantly above the figure (8.4\%) recorded for state school students within Queensland (Queensland Government 2011). The school leadership structure is complex. The school is led by the Principal, who holds executive power of the school educational vision and administration. He is supported in this role by a deputy principal, who assists him in the development and articulation of the school vision and who is in turn supported by three assistant deputy principals who are line 
managers for different departments, guiding Heads of Department in their implementation of the school vision. The school participated in the L21CS program and established wholeschool processes for embedding studies of Asia into the school's teaching and learning programs, including an Asian language program. The school prospectus notes that the school has taken a leading role in the region to engage students with Asian culture through its involvement in the AEF Access Asia initiative.

An initial analysis of public websites indicated that globalisation had been strategically deployed as a factor in leaders’ decisions to introduce and shape Asia literacy in the school:

- [Asia literacy] is a whole-school initiative consistent with our vision of preparing students for local and global citizenship. (ACARA, 2011)

This, coupled with the primarily neoliberal view of globalisation in espoused policy, foregrounds globalisation as an overarching conceptual framework for analysis. While an economic rationale was not immediately visible in the school profile the economic 'solution' may be re-presented or challenged in the school's translation.

The primary analysis is of interview data. Semi-structured interviews were conducted with leadership staff involved in leading whole-school processes:

- Principal (hereinafter referred to as P),

- Deputy Principal (hereinafter referred to as DP) and

- Assistant Deputy Principal (hereinafter referred to as ADP), initially assigned leadership of studies of Asia to oversee development of an implementation strategy for the school as head of the Humanities department.

Interview transcripts were analysed using a process of categorisation which led to inductive identification of themes evident in leaders' rationales for taking up the imperative to 'know 
Asia', integral to which emerged a narrow/broad binary that synthesised globalisation discourses within a frog metaphor.

Bakhtin’s (1981) concept of heteroglossia offered a useful theoretical framework for reanalysing data to interrogate apparent synchronicity in leaders' discourse within the metaphor. Heteroglossia is useful to understand the polyphony of discursive possibilities that exist in the metaphor, an utterance of school leaders' “conversations” (Ylimaki 2012, p. 308). Meaning and dialogue are inseparable in Bakhtinian thought: meaning generates dialogue and dialogue is necessary to drive meaning. Explicit in this theory is the dynamism of dialogue as continuous interaction between listener and speaker, through which heteroglossia is implicit. Bakhtin’s original sense identified that:

language is heteroglot from top to bottom... 'languages’ of heteroglossia intersect each other in a variety of ways...[and] are specific points of view on the world....as such they may be juxtaposed to one another, mutually supplement one another, contradict one another and be interrelated dialogically. (Bakhtin 1981, pp. 291-92)

The specific conceptualization given by intention (Bakhtin 1981, p. 292) is therefore crucial for understanding the frog metaphor.

The metaphor is constantly in dialogue with other previous or concurrent texts and their larger discourses. These relations "are, above all, social and political relations" (Lemke 1995, p. 39). Analysis of these discourses is necessary to explore the full implications of the metaphor as an "improvement plot” (Ball et al. 2011) for the school. How narrators weave policies and school idiosyncrasies into the metaphor, and how this institutional narrative shapes imagining of school curriculum, is particularly interesting. Leaders' words are fused 
from preceding dialogues that have left residual meanings, and leaders' own perspectives that orient them toward ongoing dialogues. Lemke (1995) refers to "intertextual thematic formations (ITFs)” to explore this. ITFs magnify:

- The discourse's construction of 'the way the world is' (...representational thematic) meaning and its viewpoint toward this state of affairs (its ... attitudinal meaning) and

- The discourse's (and our own) construction of the heteroglossic relations between it and other possible discourses.

Overall, the frog metaphor is explored as a living utterance of policy arising from leaders’ dialogue with policy and localised context:

having taken meaning and shape at a particular historical moment in a socially specific environment, [it] cannot fail to brush up against thousands of living dialogic threads, woven by socio-ideological consciousness around the given object of an utterance; it cannot fail to become an active participant in social dialogue... as a continuation of it and as a rejoinder to it. (Bakhtin 1981, pp. 276-77)

\section{Metaphor}

As the person responsible for the school, P determines the school's agenda and represents himself as the primary enabler of Asia-literate policy at the school:

in terms of my general influence as a leader in the school I mean it was my decision firstly to become involved with these things...I did make a very conscious decision that I would do something about it and that we needed to have discussions here about how we could move the agenda forward - that 
was a very conscious decision where I would say that my role as a leader was important. (p. 10)

Made at a time when take-up of Asia literate policy was at the discretion of schools, this decision is significant in highlighting P's agency and engagement with the ““real’ business” of visionary and enabling leadership (Newman 2005, p. 725). Both DP and ADP position their enactment roles as secondary to P, yet complementary in crucial ways. ADP's involvement is integral to policy implementation yet ultimately defers to P; “The principal ... was the key person, and ...I became the next person to affect change. (ADP, p. 3). DP sees her role as more about her ability to internalise the initiative first, so as to better support the initiative across the wider school and district:

- coming to an understanding of myself, personally, and then being able to develop work with the staff to develop the curriculum (p. 2)

- we have worked very hard to engage our cluster in developing a strategic plan. I worked with ADP on that. (p. 6)

The decision to situate policy in Humanities signals further agency: I looked for the department that I thought we would have most success in and obviously Social Sciences or Humanities, was a department where that would easily blossom because of the nature of the studies and I engaged our Head of Department $[A D P]$ who was obviously a very passionate and hard working person and very much on-side and she became the program leader in our school. $(P, p .5-6)$ 
This is consistent with findings that most Australians will learn about Asia in English and the Humanities (Fitzgerald, 1995; FitzGerald, 1997; Henderson 2004; Muller 2006; Muller and Wong 1991). However, this decision widens the scope for Asia literacy to be imagined as more than an economic project in its resistance of language-driven policy. The Australian Government committed funding of A \$62.4 million from 2009-2012 to concurrent policy initiative; National Asian Languages and Studies in Schools Program (NALSSP). This policy privileges a neoliberal human capital goal for four target languages; Chinese, Japanese, Korean and Indonesian to:

build a more productive and competitive nation. This is beneficial for our economy, community and individuals, creating more jobs and higher wages and overall better opportunities for all Australians. (DEEWR 2011)

This decision also acknowledges the desirability of a unified approach to policy enactment. ADP is identified as someone who is "very much on-side" (P, p. 6) and she worked to "get as much enthusiasm off the ground as we could" (ADP, p. 5). "Passionate” people are key actors in promoting Asia literacy in sites of best and innovative practice (Buchanan 2005). Acknowledgement of ADP's passion reinforces a desire for those that can share the vision of the reform: shared passion acts as a binding agent that forges agreement on the necessity of Asia literacy.

P credits himself with being the first to recognise this necessity on an AEF led study tour: I went and spent a couple of weeks in Korea...it made me aware of how narrow my view of the world was... how narrow my view of culture was... it sort of blew my mind to a certain extent so I decided I would follow this up 
and when we got back our school engaged with the $21^{\text {st }}$ century school access Asia program. (p.1-2)

Rising self-awareness of his own 'narrowness', and personal belief that the school and community are implicit in this: "made me think how narrow the view of most people I knew here in [Birdtown] was” (P, p. 2). P's personal experience catalytically shapes his 'take' (Braun et al. 2010) on policy enactment. His tour experience, coupled with deep contextual knowledge resulting from a long established tenure at the school of over 30 years, inform his school vision.

'Narrowness' manifests as a key theme in his vision for the school and, as an extension of this, his vision for the wider community. He positions himself as a community leader, a sort of public intellectual that has responsibility within the community to "push[ing] the edges a bit” to elicit 'broader' views:

For the last two speech nights, graduation and awards night I have purposefully chosen people to speak about with Asian background because I want to promote this theme... This year ... I'm thinking about doing ... Ahn Do, he has a book out at the moment called The Happiest Refugee and he describes very clearly his life, especially the harrowing trip they had here on a boat, he was a refugee who came here illegally on a boat initially from Vietnam... they survived everything and here is a man loved by, he's a comedian, a TV star and he came out in a refugee boat, and yet there is so much antagonism in our community towards the boat people... some people would say don't let them in and here is a person that snuck in, somehow, and has been amazingly successful and I am going to do my speech this year 
purposely on that and one day I might have someone jump up... or disagree but I haven't had that yet because I think it is important that our community understand that they shouldn't jump to conclusions and they shouldn't be too redneck about these things... I keep pushing the edges a bit. (p. 8-9)

Speaking as a public intellectual contributes further nuance to the articulation of policy. $\mathrm{P}$ identifies his major rationalisation that the people of Birdtown are potentially narrow in their views. He asserts that they should not be "too redneck", a colloquialism for suggesting their lack of knowledge has prejudiced them against Asian boatpeople. The community "should not jump to conclusions”, but instead be more open, justifying his choice of topic for speech night as an attempt to 'broaden' the community's exposure to such topics. P assumes there will be resistance, yet simultaneously embraces his agency to "push the edges" of their narrowness.

His capacity to commit to his transformative agenda is potentially constrained by tensions of a 'narrow' and 'redneck' community, however these tensions are repositioned to justify the imperative, situating his visions in a 'broader' globalisation agenda. P's rationale as public intellectual is synchronous with the beliefs and experiences shaping his school vision. The “'principle of integration', which coheres policy and the school itself” (Ball et al. 2011, p. 627), is a metaphor of a frog in the well, first applied to the school by P:

I always use Li Cunxin’s book Mao's Last Dancer and the story of the Frog in the Well as an iconic story to say that we need to take all the little frogs from [Wellington-suburb of Birdtown] and show them that there is a world beyond [the major football] stadium, that there is a big world out there. (p. 2) 
This metaphor can be summarised as follows:

A little frog lived at the bottom of a well. He could see the sky but the only world he knew was his well. One day he met a frog who lived in the world above. The little frog asked the frog from the world above to come and play in the well. The frog from the world above did not want to go into the well because it was so small. The little frog didn’t believe that his life in the well was limited and asked his grandfather if there really was a big world up above, and if so why didn't the little frog know about it. His grandfather confirmed that the big world did exist, and that he hadn't told the little frog about it because his destiny was in the well and the little frog couldn't get out. This made the little frog determined to escape the well. (Cunxin 2003) Knowledge of the 'big world' is akin to knowledge of Asia. Students are positioned as 'narrow frogs', which need to 'broaden' their outlook to escape the well. The narrow/broad binary of the metaphor resonates in responses of supporting leaders:

DP-we use here the frog in the well story a lot where little kids from [Wellington-a suburb of Birdtown], young people from this district who think [the] Stadium is the centre of the universe... they haven't been encouraged to look outside that world but they need to. (p. 5)

$A D P$ - we have a large number of students here who truly and utterly believe that [Birdtown], or [Ville-a neighbouring city] is the end of the Earth and we know that in order to be successful in the $21^{\text {st }}$ century they are going to need to be able to operate on a scale much broader than that (p. 5)

While the synchronicity here is interesting, leaders' dialogue reveals differences in their imagining of metaphor enactment, and spaces they see for narrative possibilities. 


\section{Narrow}

In the first instance, students are positioned as frogs that need to escape their 'well'; defined by the boundaries set by the outer suburb of Birdtown, Wellington, and the town's football stadium. Integral to the metaphor of students as frogs in the well is a discourse that conceptualises students as 'narrow' minded, drawing on imagery of the frog in the well, looking up at a small space of sky.

Ideological representations of low SES create an ITF of 'narrowness'. The representational meaning is established by P; "we have a very working class school - the ICSEA [Index of Socio-Educational Advantage] score is very low” (p. 2). This meaning is influenced by the government website on schools, Myschool which uses the ICSEA value to profile schools, on which the value for the school sits below median. Additionally, low SES is commonly defined as negatively impacting on social, cultural and economic resources in educational contexts. P's experience of the school community has led him to conclude that "the problem is that when you live in an area, especially a low socio-economic area where there isn't a lot of education there is no demand for it" (p. 11). This attitudinal meaning positions low SES as a disadvantage and synonymous with lack of aspiration.

In this deficit discourse home fails to equip students socially and/or culturally for engagement with Asia. Students' home environment is identified as a 'narrow' site that fails to cultivate aspiration:

DP - we want to support, of course, what happens at home and the perspectives of the kids at home but they have also got to see that sometimes 
there are bigger perspectives than that and I think our students here really need that. (p. 5)

This is supported within the school profile, written by $\mathrm{P}$ and published on the AEF website as part of the school's participation in L21CS:

students ... generally come to [school] with limited international knowledge, understandings and experiences. I believe strongly that it is the responsibility of the school to create opportunities for students to build their social capital so they can take their place confidently and successfully as responsible citizens in an increasingly global world. (ISHS 2010)

Leaders’ responses typically equate limited cultural capacity with limited exposure to something 'bigger' or 'broader', intimating a preference for the big world outside the well. A twenty-first century skill set is perceived as lacking, yet necessary for successful escape from the well:

ADP- ultimately we deal with a socio-economic status of students that is very diverse, we have a large number of students here who have significant disadvantage, ... and we know that in order to be successful in the $21^{\text {st }}$ century they are going to need to be able to operate on a scale much broader than that. (p. 5)

This skill set is also emphasised in the Melbourne Declaration on Educational Goals for Young Australians (MCEETYA 2008). Also emphasised in the Melbourne Declaration is a social agenda for equity, under which low SES is associated with "socioeconomic disadvantage” (MCEETYA 2008, p. 7). Positioning the latter as a social problem (Newman 2005), leaders clearly foreground it and seek to broaden the home environment in response. 
P aspires towards a "better society" in which "mister ordinary mum and dad who are going to live in suburbia all their lives” can “know about and understand Asian cultures” (p. 9). For DP, this culminates in " $a$ point where students came here expecting and wanting to be taught by people from different cultures ... being open to that.” (p. 13). Both P, in his comments about speech night, and DP cite the importance of not just broadening students but the wider community as well:

DP - as an educator ... you have to actually be willing to work within a community, to help a community come to new understandings. (p. 13)

The chain of intertextuality in discourse related to narrowness builds a dominant discourse that equates low SES with the assumption that students do not aspire to escape the well. This indicates normative assumptions on behalf of leaders that students do not aspire to escape because "there is no demand for it" (P, p. 11) and that they and their community need to “come to a new understanding” (DP, p. 13) regarding the imperative of escape.

Mandating students 'demand' to escape the well is problematic, regardless of an unproblematic acceptance that there really is "no demand for it" (P, p. 11). Appadurai (2004) suggests that it is not that the poor do not aspire, but that their capacity to aspire is not equally concentrated due to the unequal distribution of social, cultural and economic resources. Singular focus on resources such as cultural capital is supported by presenting the home environment as disadvantaged. In contrast, aspiration can be conceptualised as navigational capacity; dependent on an ability to both imagine the future in a detailed way and transfer this imaginary into outcomes (Smith 2011), manoeuvring across “a map of a journey into the future” (Appadurai 2004, p. 76). Appadurai (1996, p. 5) asserts that “imagination has now become a part of the quotidian mental work of ordinary people” who 
have a wider set of future options than ever before. Contemporary globalisation has led to the rise of imagination “ “work' in a variety of ways with which people define themselves and construct their relations to others” (Rizvi 2006, p. 194). Frogs are encouraged to aspire and imagine a future outside of the narrow well as it is imagined they will engage with Asian culture and 'broaden' their lives to become competent twenty-first century citizens. School leaders' commitment to support an escape from the well could be a catalyst for increasing students’ navigational capacity. Resultant curriculum change that enriches students' experience as learners within education institutions and builds on their limited access to social, cultural and economic resources can affect what students perceive as both desirable and realistically achievable (Smith 2011).

This chain of intertextuality, however, highlights an oppositional, and in significant ways, a cautionary discourse. Assuming students, prior to the implementation of Asia literate policy, did not aspire at all further diminishes their capacity, delimiting rather than inspiring students to broaden narrow perspectives:

dominant conceptions of aspiration imply potentially offensive and normative assumptions about the value and legitimacy of particular educational pathways, forms of employment and life projects. That is, those who do not aspire... are assumed to have lower aspirations. (Sellar et al. 2011, p. 38) The narrative to challenge 'narrow' frogs potentially restricts frogs' future choices, albeit in subtle forms. Further investigation is warranted here to determine if the focus is on telling students they must escape, 'saving' them from the well, or empowering them with increased capacity, should they choose to leave. 


\section{Broad}

Consensus building among school leaders justifies enactment of policy in terms of the extent to which it can 'fix' what is viewed as lacking in frogs who live only in the well.

Globalisation is implicated in discourses of narrowness and aspiration as part of this 'fix' and is drawn on in multiple ways to legitimate school change that might otherwise be resisted (Newman 2005). An ITF of globalisation forms a dominant discourse around the importance of 'broadening' students and works in important ways to support deficit discourses of 'narrowness'.

Globalisation is represented as integral motivation for increasing, therefore 'fixing', diminutive student resources:

$P$ - it is important that students get a global perspective because we live in a global world and if they don't they are going to be very narrow people and that sort of narrowness breeds intolerance. (p. 12)

DP - students here have very little exposure to other cultures other than their own, in any real way, and I think if they are going to become really strong global citizens who can make some sort of contribution they are going to need a lot more. (p. 3)

$A D P$ - in order to be successful and engage globally Australia has to be Asia literate, or, we will find ourselves unable to engage on a global scale. (p. 1) 
Consensus on the importance of being "global”, equating this with 'broadening', indicates that globalisation has been strategically deployed as a factor in leaders’ decisions. The inevitability of global economy underpinned by primarily neoliberal views of globalisation is a dominant view. At the school economic rationale saturates a compelling discourse of globalisation that equates Asia-literate knowledge with being "successful in the $21^{\text {st }}$ century" (ADP, p. 5):

$P$ - Well, if you read the statement [National Statement for Engaging Young Australians with Asia in Australian Schools]...it is very good, it explicitly talks about a number of factors - one of them, I don't know if I can remember them all, one of them is obviously economic...where would we be without the mining industry and China buying our resources at the moment... but politically China is undoubtedly a major nation of the world and it may even take over in the next 10 to 20 years to became THE major world power and obviously we need to be aware of that. (p. 3-4)

Firstly, Asia literacy is positioned as a knowledge product that can secure economic connections with Asia as cited within the policy statement referred to: “Australia's future economic strength requires Australians to be knowledgeable and confident in relationships with the peoples of Asia” (AEF, 2006b, p. 6). A perceived absence of Asia literate knowledge is seen as a problematic for the knowledge economy.

Secondly, governing knowledge produced by the AEF is constituted by discourses of preparing an Australia workforce that is globally competitive and can capitalise on economic 
opportunities available in Australia and the Asian region. Concerns about Korea's growing knowledge economy align with this call for a globally competitive workforce:

DP - if you look at Korea and the way Korea has really improved in terms of PISA type data, they are doing really good things in terms of education and if you just think about the work ethic of most Asian cultures it is very strong...their knowledge economy is growing and ... we have to compete with that and I don't think that many Australians have really, until recently, had much appreciation of that. (p. 1)

Juxtaposed with economic discourse is an alternate imagining of globalisation. DP also imagines a more harmonious future:

in terms of having some sort of peace in the world I think we have really got to get to greater depth of understanding between different people in the world and what their perspectives are and at the moment that doesn't happen. When you think about it, there is a lot of conflict...and a lot of it's to do with cultural misunderstanding and I think that is something that we really have to prepare the next generation to address. (p. 1-2)

This discourse resonates in policy:

Young Australians who possess a regional and global mindset and skill-set will be able to build a creative, prosperous and socially cohesive Australia and develop harmonious regional and global communities that can work together to resolve the issues that affect us all. (AEF 2011, p. 2) 
Repetitious calls to increase students' cultural resources draw attention back to the assumption that students lack social and cultural capacity. Presenting Asian perspectives as facilitating “deep knowledge” (DP, p. 1) and the ability to "engage” and "interface meaningfully with Asian culture” (P; ADP, p. 1) confirms the importance of intercultural understanding. Furthermore, this agreement supports a mutually beneficial relationship with knowing other cultural groups, particularly Aboriginal and Torres Strait Islander cultures. At the time of planning for Asia literacy in the curriculum, state and national governments also mandated that Indigenous perspectives be addressed. Initially, the complementary nature of the two priorities was not identified, however work within the L21CS program provided impetus for greater alignment between potentially competing presences:

$A D P$ - the more we have gone into it the more alignment we have seen. We started off saying an "Asia literate [school]", then we looked to an "Internationally minded [school]" and as we continued along that journey we really started to move towards a language of intercultural understandings. So, once we moved to that position where we had a greater depth of knowledge about what it was we wanted... alignment has grown more and more. So, rather than trying to cram in a unit on Indigenous Australia and cram in a unit on Asia we are really teaching to something that is broader. (p. 7)

This pairing highlights similar concerns regarding the problematising of cultural politics, challenging Eurocentric curriculum and the complexities of cross-cultural understanding, while at the same time disregarding competition for space as discrete bodies of knowledge. Repackaging Asia literacy in this way allows the metaphor to meet local agendas: drawing on 
and accommodating the contextual factors of a higher than average enrolment of Aboriginal and Torres Strait Islander students and parallel National Curriculum cross-curriculum priority; 'Aboriginal and Torres Strait Islanders histories and cultures’.

\section{Imagine, or be imagined?}

Voluntary take-up of policy that promotes cultural engagement with Asia is not necessarily an obvious choice for a low SES school with high enrolment of Aboriginal and Torres Strait Islander students. School leaders exercise agency by "pushing the local...understood not just in a spatial sense but as symbolically condensing a range of attachments and identifications constituted around a 'we'”(Newman 2005, p. 727) in a metaphor that is distinctive to the school. Leaders' agency in both choosing to enact and creatively imagine policy in a localised narrative is intriguing, taking them beyond the notion that they are merely gatekeepers. Driven by pressures of globalisation informing national policy, and underpinned by local understandings of the implications of globalisation, heteroglossic discourses are mobilised to appropriate policy in accordance with local strategic priorities, translating it rather than simply 'implementing' it in the school context. School leaders interpret policy to rationalise demand for Asia literacy at the school by drawing on global discourses to drive change, privileging discourses of socioeconomic disadvantage as social problem and repackaging policy to meet local discourses (Newman 2005) regarding Aboriginal and Torres Strait Islander students. These discourses are juxtaposed in the frog metaphor to act in mutually supplementary ways. Imperative to this is the assumption that students must escape the well, however without intercultural knowledge of Asia they lack resources to do so, reflecting an empowerment discourse to 'free' the frogs and prepare them to be active and competent citizens. Tensions between policy agendas and leaders' vision 
manifests in contradictory social agreements the metaphor seeks to make with those that take it up. Discourses of these agreements are oppositional, yet interrelated dialogically as incongruous aspects of a twenty-first century skill set; economic and competitive, or philanthropic and harmonious?

Initially, the metaphor appeals to the latter as a social covenant, built through:

- A sense of identity that coheres the metaphor to the school context, making links to key contextual factors such as SES and above average enrolment of Aboriginal and Torres Strait Islander students,

- A sense of responsibility to help frogs 'escape' the well and

- Confines of contextual factors.

The covenant is maintained by a "sense of identity, obligation, duty, responsibility and reciprocity" (Sergiovanni 1998, p. 44) to "make a significant change to the lives of, if not all, at least a significant number of kids” (DP, p. 11).

Tensions between empowerment discourses, changing lives to "have a better society” (DP, p. 9), and those that seek to delimit students, are problematic. A school vision has the potential to do either, as well as in unintentionally contradictory ways, both. The "improvement plot" (Ball et al. 2011) to empower frogs is integral to school change and leaders as narrators are engaged in a "politics of hope relate[d] to the encouragement of students [and teachers] to imagine other, to imagine a better world” (Wrigley et al. 2012, p. 105). Resultant curriculum reform is presented as crucial to 'broadening' mindsets to increase capacity of students to imagine and navigate ‘better' futures. 
'Better', however, is inherently normative, and intertwined with school leaders' unusually synchronous beliefs and experiences. The metaphor is presented as a stimulant (Leithwood et al. 2008) for teachers to similarly become:

'the guardians' of the idea of an open cosmopolitan neighbourhood of 'likeminded’ individuals... an approach which, as Vanessa Andreotti notes, may end up in teachers promoting, “a new 'civilising mission' as the slogan for a generation to take up the 'burden' of saving/education/civilising the world” (2006, 83). (Langmann 2011, p. 403)

The social covenant presents a powerful moral purpose to school staff to make "significant change”' (DP, p. 11), engaging moral purpose as a catalytic force for further drivers of change (Fullan et al. 2005). However, it is unclear if teachers and 'frogs' will be empowered by the metaphor or merely bound to comply with it. Furthermore, the moral purpose of emancipating frogs positions Asia literacy as putting capital into frogs and stems from a premise that students are culturally ignorant. This imperative, as already noted, is perhaps partially driven by a social agenda manifest in umbrella policy statements that call for commitment to "ensure that socioeconomic disadvantage ceases to be a significant determinant of educational outcomes” (MCEETYA 2008, p. 7). While undeniably a desirable outcome, temptation to save and redeem frogs for a 'likeminded' future puts at risk frogs’ agency to imagine their own futures. As Ylimaki (2006, p. 623) cautions, “visions crafted by a formal leader are inherently undemocratic and do not necessarily engender ownership” . Ironically, this reveals a possibility that school leaders' creative work is deeply flawed, bound by 'narrowness' that asks students to neglect their own imaginative work for their futures and instead conform to normative aspirations. Rather than liberate, the metaphor potentially delimits those that use it to shape their own future pathways. 
On the other hand, the metaphor is also driven to some extent by economic and competitive discourses of espoused policy included in narratives of social contract. The metaphor as contract is an example of "curriculum reform [that] has been linked to the reconstitution of education as a central arm of national economic policy” (Rizvi and Lingard 2010, p. 96). A promise of gain is highlighted in implicit contractual discourse that offers incentives of increased job opportunities if frogs endeavour to escape the well. While not the only incentive offered to entice students out of the well, increased human capital is a potentially overwhelming discursive possibility due to its alignment with dominant policy discourse. This impedes notions of Asia-literate knowledge for harmonious and peaceful purposes, or necessarily cultural rather than economic ends.

Overall, the metaphor provides a rich opportunity to challenge economic and competitive notions of globalisation, however risks around normative assumptions of aspirations are clear. The conceptual framework of analysis utilised here provides a "framework to capture the fluidity of policy processes” (Lendvai and Stubbs 2007, p. 189) across policy trajectories, realising that policy exists as a living utterance (Bakhtin 1981). Situated within education policy trajectory, the school constitutes a site for policy translation, at which the space for possibility is explored in leaders' heteroglossic discourses, employed to condense espoused and enacted policy in the frog metaphor. Ultimately, this space makes possible a particular globalised imaginary, delimiting what is recognised as aspiration for 'frogs'. Those who feel that leaving the well is not possible or desirable risk being constructed as having 'low' aspirations and in some way 'deficit'; this points to dangers in taking up policy enactment as a form of social covenant. Drawing on Taylor's (1994) notion of recognition, regarding the struggle of cognisance afforded to different cultural groups, when under-participation in Asia literacy is explained as a result of low aspiration where there is "no demand for it" (P, p. 11) 
because students “haven't been encouraged to look outside that world but they need to" (DP, p.5 ), this perpetuates a normative recognition of Asia literacy as valuable knowledge (Sellar et al. 2011) andsupported by espoused policy (Salter 2013). The economic rationale of social contract is similarly problematic, suggesting that Asia literacy will enable many from disadvantaged backgrounds to be more competitive in the workforce. It is by no means clear that inclusion of Asia literacy in curriculum will deliver better returns than the status quo.

\section{Imagining policy enactment}

The call to 'know Asia’ in national policy formation is enacted at Ibis State High School by appropriating and mobilising current national policy to promote Asia literacy in ways that adapt it to the local social context and particular organisational imperatives and structures of the school. School leaders' deep contextual knowledge enables them to translate policy into the educational, professional and social ethos of the school. They deploy the frog metaphor to position aspiration as a cultural capacity for realising a collectively imagined future. Knowing Asia dismantles the well, as well as enables the frogs to leap from the well. Binary opposites 'narrow' and 'broad' are juxtaposed to mutually supplement one another. Furthermore, leaders simplify complex relationships that encompass hierarchy and privilege of certain knowledges, functioning at the school site to shape how they rationalise demand for Asia literacy. This extends Ball's (1993) notion of the trajectory of policy to show how school leaders can be understood to be engaged in crucial ways in the transformation, not merely the passive implementation, of policy that is essentially handed down from elsewhere.

Allusion to a 'good news story' is not intentional. This study demonstrates how leaders mobilise the school vision to negotiate deficit in schools both intentionally and unintentionally. There has been a conscious and deliberate use of agency to enact Asia 
literacy to recognise and mediate 'narrow' resistance. The way this enactment has been taken up makes it difficult to see it as unapologetic rhetoric. The school has struggled with the implementation of Asia literacy and while this vision is not yet realised, there is a clear notion that this struggle is worth the commitment to "push[ing] the edges a bit" (P, p. 9). What may be even more interesting is teachers' rejoinder to this vision, and how they border think the pregnant space (Andreotti 2011) of Asia literacy curriculum open before them. Asia literacy, despite its mandated and seemingly fixed presence in the emerging National Curriculum, exists as a living utterance; a policy initiative in continuation, affected and being affected in perpetual dialogue.

\section{Notes}

1. Defining 'Asia' is widely acknowledged to be problematic. For example, education policy uses Asia as a geographic point of reference, covering complex subregions that form the area most Australian schools are likely to cover:

- North-east Asia including China, Japan, North Korea, South Korea and Taiwan

- South-east Asia including Indonesia, Myanmar (Burma), Thailand, Malaysia, Brunei, Singapore, Vietnam, Laos, East Timor, the Philippines and Cambodia

- South Asia including India, Pakistan, Nepal, Bhutan, Bangladesh, Sri Lanka and the Maldives. (AEF 2006b, p. 7)

The obvious heterogeneity of nation-states contained within boundaries is problematic when not acknowledged. Singh (1995) cites that such classifications are due to Australia’s economic, technological and political interests in these geographic regions. Certainly, policy recognises that Asia can also be described in "cultural, religious, historical and 
linguistic” (AEF 2006b, p. 7) terms, acknowledging the contestability of geographical terms. Interrogating boundaries may seem superficial compared to bigger intellectual challenges of Asian studies, yet it foregrounds the complexity of selecting and defining the study of Asia (Williamson-Fien 1994). In this article where the term Asia is used, it should be read as if written between quotation marks (Broinowski 1992; Singh 1996), such is the plethora of possible definitions. Likewise for the term 'Asia literate', which is defined here as a complex endeavour of studies of Asia that encompasses both Asia and "cultural literacy" (Muller 2006; Muller and Wong 1991), recognising that static and singular notions of Asia and Asian culture are inadequate (Broinowski, 1992; Rizvi, (1997).

\section{References:}

Andreotti, V.D.O. 2011. (towards) decoloniality and diversality in global citizenship education. Globalisation, Societies and Education 9, no. 3-4: 381-97.

Appadurai, A. 1996. Modernity at large: Cultural dimensions of globalization. Minneapolis: University of Minneapolis.

Appadurai, A. 2004. The capacity to aspire: Culture and the terms of recognition. In Culture and public action: A cross-disciplinary dialogue on development policy, eds Walton, $\mathrm{M}$ and Rao, V, 59-84. Washington: Wold Bank Publications.

Asia Education Foundation. 1995. Studies of Asia: A statement for Australian schools. Carlton: Curriculum Corporation.

Asia Education Foundation. 2006a. A guide to implementing the national statement for engaging young Australians with Asia in Australian schools: Teacher and school resource. Carlton: Curriculum Corporation.

Asia Education Foundation. 2006b. National statement for engaging young Australians with Asia in Australian schools. Carlton: Curriculum Corporation.

Asia Education Foundation. 2008. Leading 21st century schools: Engage with Asia (tool kit modules): Asia Education Foundation.

Asia Education Foundation. 2011. National statement onAsia literacy in Australian schools 2011-2012. Accessed November 12011.

http://www.asiaeducation.edu.au/verve/_resources/AEF_NationalStatement_[20Sept2 011].pdf

Asia Education Foundation. 2012a. Asia education foundation submission to the Australian government white paper on Australia in the Asian century.

Asia Education Foundation. 2012b. The Australian curriculum: An Asia literacy game changer.

Asia Education Foundation. 2012c. Building demand for Asia literacy: What works: The University of Melbourne. 
Asia Education Foundation. 2012d. Submission to the Australian government white paper on Australia in the Asian century, 25.

Australian Curriculum Assessment and Reporting. Asia and Australia's engagement with Asia.

Australian Curriculum Assessment and Reporting Authority. 2011. Ibis State High School. 2011 Accessed June 13 2011. http://www.myschool.edu.au/

Australian Government. 2011. White paper on Australia in the Asian century: Terms of reference.Accessed June 302012. http://www.stephenjones.org.au/assets/Uploads/Asian-Century-White-Paper-ToRs.pdf

Australian Government. 2012. Australia in the Asian century. 2012 Accessed June 122012. http://asiancentury.dpmc.gov.au/

Bacchi, C. 1999. Women, policy and politics: The construction of policy problems. London: SAGE Publications.

Bacchi, C. 2000. Policy as discourse: What does it mean? Where does it get us? Discourse: Studies in the Cultural Politics of Education 21, no. 1: 45-57.

Bacchi, C. 2009. Analysing policy: What's the problem represented to be? Frenchs Forest: Pearson Australia.

Bakhtin, M.M. 1981. Discourse in the novel. In The dialogic imagination, ed. Holquist, M, 259-422. Austin: University of Texas Press.

Ball, S. 1993. What is policy? Texts, trajectories and toolboxes. Discourse: Studies in the Cultural Politics of Education 13, no. 2: 10-17.

Ball, S. 1994a. Education reform: A critical and post-structural approach. Buckingham: Open University Press.

Ball, S. 1994b. What is criticism? A continuing conversation? A rejoinder to Miriam Henry. Discourse: Studies in the Cultural Politics of Education 14, no. 2: 108-10.

Ball, S., M. Maguire, A. Braun and K. Hoskins. 2011. Policy actors: Doing policy work in schools. Discourse: Studies in the Cultural Politics of Education 32, no. 4: 625-39.

Braun, A., S.J. Ball, M. Maguire and K. Hoskins. 2011. Taking context seriously: Towards explaining policy enactments in the secondary school. Discourse: Studies in the Cultural Politics of Education 32, no. 4: 585-96.

Braun, A., M. Maguire and S.J. Ball. 2010. Policy enactments in the UK secondary school: Examining policy, practice and school positioning. Journal of Education Policy 25, no. 4: 547-60.

Broinowski, A. 1992. The yellow lady: Australian impressions of Asia. Melbourne: Oxford University Press.

Buchanan, J. 2005. Towards a future for the study of Asia in Australia. Asia on a shoestring? The Social Educator December: 39-49.

Commonwealth of Australia. 2012. White paper: Australia in the Asian century. Accessed October 12 2012. http://asiancentury.dpmc.gov.au/sites/default/files/whitepaper/australia-in-the-asian-century-white-paper.pdf

Cranston, N., M. Kimber, B. Mulford, A. Reid and J. Keating. 2010. Politics and school education in Australia: A case of shifting purposes. Journal of Educational Administration 48, no. 2: 182-85.

Cunxin, L. 2003. Mao's last dancer. Camberwell: Penguin.

Day, C., P. Sammons, D. Hopkins, A. Harris, K. Leithwood, Q. Gu and E. Brown. 2010. 10 strong claims about successful school leadership. Nottingham: The National College for Leadership of Schools and Children's Services.

Department of Education Employment and Workplace Relations. 2011. National Asian languages and studies in schools program - overview. Accessed 12 October 2011. http://www.deewr.gov.au/schooling/NALSSP/Pages/default.aspx 
Fitzgerald, J. 1995. Asian studies and the national interest. Quadrant, no. January-February: 53-56.

Fitzgerald, S. 1997. Is Australia an Asian country? Sydney: Allen \& Unwin.

Fullan, M.G., C. Cuttress and A. Kilcher. 2005. 8 forces for leaders of change. Journal of Staff Development 26, no. 4: 54-58, 64.

Gale, T. 1999. Policy trajectories: Treading the discursive path of policy analysis. Discourse: Studies in the Cultural Politics of Education 20, no. 3: 393-407.

Glen, M. 2009. Distributed leadership: A case study in a Queensland secondary school. Doctor of Education, Griffith University.

Grimaldi, E. 2012. Analysing policy in the context(s) of practice: A theoretical puzzle. Journal of Education Policy: 1-21.

Henderson, D. 2003. Meeting the national interest through Asia literacy - an overview of the major stages and debates. Asian Studies Review 27, no. 1: 23-53.

Henderson, D. 2004. Why studies of Asia deserve a place in Australia's history curriculum. EQ 2, no. Talking History: 21-22.

Henry, K. 2012. Speech to the 2012 biennial conference of the Asian studies association of Australia.: Asian Studies Association of Australia.

Henry, M. 1993. What is policy? A response to Stephen Ball. Discourse: Studies in the Cultural Politics of Education 14, no. 1: 102-05.

Ibis State High School. 2010. School profile: Asian Education Foundation.

Langmann, E. 2011. Representational and territorial economies in global citizenship education: Welcoming the other at the limit of cosmopolitan hospitality. Globalisation, Societies and Education 9, no. 3-4: 399-409.

Leithwood, K., A. Harris and D. Hopkins. 2008. Seven strong claims about successful school leadership. School Leadership \& Management 28, no. 1: 27-42.

Lemke, J. 1995. Ed. Luke, A. Textual politics: Discourse and social dynamics Critical perspectives on literacy and education. London: Taylor \& Francis Ltd.

Lendvai, N. and P. Stubbs. 2007. Policies as translation: Situating transnational social policies. In Policy reconsidered: Meaning, politics and practices, eds Hodgson, S and Irving, Z. Bristol: Policy Press.

Mcrae, D. 2001. Change is a journey, not a blueprint. Melbourne: Asia Education Foundation.

Ministerial Council on Education Employment Training and Youth Affairs. 2008. Melbourne declaration of educational goals for young Australians. Accessed June 302012. http://www.curriculum.edu.au/verve/_resources/National_Declaration_on_the_Educat ional_Goals_for_Young_Australians.pdf

Muller, W. 2006. The contribution of 'cultural literacy' to the 'globally engaged curriculum' and the 'globally engaged citizen'. The Social Educator, no. August: 13-15.

Muller, W. and M. Wong. 1991. Asian studies in Queensland schools. In Issues in Education, ed. Curriculum, MCCO.

Newman, J. 2005. Enter the transformational leader. Sociology 39, no. 4: 717-34.

Nudzor, H. 2009. Re-conceptualising the paradox in policy implementation: A postmodernist conceptual approach. Discourse: Studies in the Cultural Politics of Education 30, no. 4: 501-13.

Owen, J., I. Ling, P. Andrew and M. Ling. 2006. The future of studies of Asia and Australia in Australian schools: An evaluative investigation: Asia Education Foundation.

Ozga, J. 2000. Policy research in educational settings: Contested terrain. Buckingham, UK: Open University Press.

Pang, D. 2005. Education for location? The policy context of 'becoming Asia literate' in five western countries/regions in the 1990s. Comparative Education 41, no. 2: 171-98. 
Peters, M. 2001. National education policy constructions of the "knowledge economy": Towards a critique. Journal of Educational Enquiry 2, no. 1: 1-22.

Queensland Government. 2011. Embedding Aboriginal andTorres Strait Islander perspectives in schools: A guide for school learning communities, ed. Department of Education and Training.

Rizvi, F. 1997. Beyond the east-west divide: Education and the dynamics of Australia-Asia relations. Australian Educational Researcher 24, no. 1: 13-26.

Rizvi, F. 2006. Imagination and the globalisation of educational policy research. Societies and Education 4, no. 2: 193-205.

Rizvi, F. and B. Lingard. 2010. Globalizing education policy. London: Routledge.

Rudd, K. 1994. Asian languages and Australia's economic future: A report prepared for the council of Australian governments on a proposed national Asian languages/studies strategy for Australian schools, ed. Governments, COA. Brisbane: Queensland Government Printer.

Salter, P. 2013. The problem in policy: Representations of Asia literacy in Australian education for the Asian century. Asian Studies Review 37, no. 1: 3-23.

Sellar, S., T. Gale and S. Parker. 2011. Appreciating aspirations in Australian higher education. Cambridge Journal of Education 41, no. 1: 37-52.

Sergiovanni, T.J. 1998. Leadership as pedagogy, capital development and school effectiveness. International Journal of Leadership in Education 1, no. 1: 37-46.

Singh, M. 1995. Translating studies of Asia: A curriculum statement for negotiation in Australian schools. Belconnen: Australian Curriculum Studies Association.

Singh, M. 1996. Studying Asia for the national economic interest: An analysis of the Australian governments' strategy for schools. Discourse: Studies in the Cultural Politics of Education 2, no. 17: 153-70.

Smith, L. 2011. Experiential 'hot' knowledge and its influence on low-ses students' capacities to aspire to higher education. Critical Studies in Education 52, no. 2: 165-77.

Taylor, C. 1994. The politics of recognition. In Multiculturalism: Examining the politics of recognition, ed. Gutman, A, 25-73. Princeton: Princeton University Press.

Williamson-Fien, J. 1994. Facing the tiger: The problematics of Asian studies education. Discourse: Studies in the Cultural Politics of Education 15, no. 1: 75-87.

Wrigley, T., B. Lingard and P. Thomson. 2012. Pedagogies of transformation: Keeping hope alive in troubled times. Critical Studies in Education 53, no. 1: 95-108.

Ylimaki, R.M. 2006. Toward a new conceptualization of vision in the work of educational leaders: Cases of the visionary archetype. Educational Administration Quarterly 42, no. 4: 620-51.

Ylimaki, R.M. 2012. Curriculum leadership in a conservative era. Educational Administration Quarterly 48, no. 2: 304-46. 